\title{
Coming to Grips with Change: The Initial Training of Geography Teachers in Hong Kong
}

\author{
Philip Stimpson \\ Faculty of Education, The University of Hong Kong, Hong Kong, China
}

Hong Kong styles itself as 'the city that never sleeps', 'the ever changing city'. The dynamism and pace of change in teacher education, however, has to be seen as laggardly in comparison. This is not to say there has been no experiment but changes have been piecemeal and 'add-ons'. Teacher education in Hong Kong has now, however, reached something of a hiatus brought about by changing conditions in the education system of the SAR (Special Administrative Region of the People's Republic of China). This paper is concerned with the impact of these changes in the teacher education curriculum for the initial training of geography teachers.

\section{Changing Contexts}

The initial training of secondary geography teachers is carried out at three of the seven universities with the primary sector being catered for by an Institute of Education born out of the amalgamation a decade ago of the Colleges of Education. The initial training of secondary geography teachers takes the form of a one-year pre-service full-time Postgraduate Diploma in Education (PGDE) or a two-year part-time PGDE taken in the early years of teaching. In addition, a small number of beginning geography teachers working in junior secondary or primary schools come through a Bachelor of Education route. There is no centrally mandated teacher education curriculum, although one may be on the horizon, and programmes vary from institution to institution within a common theme.

Geography teacher trainers in Hong Kong have not been unaware of global trends in teacher training. Ideas such as school-university partnership, problembased learning, and first steps on professional ladders have been strong in the rhetoric if not always so apparent in practice. Changing social and economic conditions in the SAR, however, have caused geography teacher educators, as others, to think more seriously about substantive, sustained (and sustainable) reform in the ways teachers are trained.

Two changes in particular have spurred reform, one curricular and one financial. During the late 1980s and into the 1990s, in common with many countries around the world, Hong Kong engaged in a serious review of its school curriculum and the consequent reorganisation that would be needed. It was only in 1978 that compulsory education to Secondary 3, or age 14-15 years, was introduced although, in practice, most young people stayed in school until Secondary 
5. The concern of Government was, for various social, demographic and economic reasons, with quantity of educational provision. The economic successes of the 1990s, rising public expectation and political reawakening in the run-up to the change of sovereignty saw a move towards an ideal of quality education for all rather than an elite.

A central plank of the new school curriculum is a move from a myriad of potential subjects to seven key learning areas (KLA) in which a reduced number of school subjects reside. For some curriculum subjects this made little difference; for example, mathematics was contained in a maths KLA. However, geography was located within Personal, Social and Humanities Education (PSHE) alongside history, economics, social studies, liberal studies and a new integrated area, Integrated Humanities $(\mathrm{IH})$. Geographers entering secondary teaching were now expected to be able to teach geography and IH. Further, the existing geography curriculum, which like its counterparts was in essence a curriculum for more able students watered down for the less academically inclined, had to be renewed.

This renewal took place in the late 1990s with a stronger focus on issues and skills but reduced thematic content. Inquiry was emphasised even more strongly than before as a core concept and one which linked it with other PSHE subjects. Moves to criterion referencing and what is in reality differentiation have been suggested since the introduction of this curriculum. The intention here is not to discuss curriculum change but rather to point to the conceptual, paradigmatic change presented and the need to reassess the way geography teachers are trained.

The curriculum reforms were broadly welcomed by curriculum developers and by teacher educators who generally work within a dual perspective of teacher training and curriculum change. Geography teacher educators were critical but supportive. The Asian financial crisis, however, has had an important influence on the training response and threatened to hamper initiatives.

Government budgetary deficit led to reduced public spending, including university funding. Universities have needed to focus their mission. The two major providers of secondary school geography teachers have been styled as research universities. Within those two institutions, there are demands to free up time for research through a reduction in the overall teaching hours given to courses. From one perspective, this may not be a bad thing as there is a general tendency to over-teach. However, professional programmes, such as teacher training, tend to be contact intensive and this has demanded a rethink in how initial training is conducted and the philosophy directing it.

Geography educators, in addition, are facing specific challenges of their own as Government attempts to micro-manage the supply of new teachers and match training numbers with likely jobs. With a young workforce in school geography departments, quotas for the training of further PSHE teachers have been drastically reduced and the viability of programmes as they exist is in question.

\section{Changing Structures}

The challenges facing the initial training of geography teachers are not unique and are ones faced a decade ago in Australia and the UK, for example. Meeting 
these challenges has required organisational and philosophical change and a refocusing on what is needed in preparing geography teachers. It demands that questions of purpose are asked and an acceptance of the need to relinquish long held practices when necessary.

\section{Organisational change}

One reaction in training has been to combine either partially or completely the training of geography teachers with those in history and economics. This offers cost effectiveness to providers and the opportunity for new teachers of geography to recognise the position of the subject perspective in the broader aims of PSHE and act against isolationism. The converse has also occurred as a new teacher education curriculum is 'negotiated' with a degree of well-intentioned preservationism.

\section{Philosophical change}

Philosophical change is perhaps more crucial (and probably more difficult) than organisational change. Geography teacher trainers have had to ask what their focus should be, why and how they should go about realising it in practice. What vision for training should guide the initial training of geography teachers? No firm answers can be articulated but trends are becoming apparent that reflect some current directions in the literature. Willis (2002) argues that most people believe that the professional development of teachers should be targeted and directly related to teachers' practice and, to the extent possible, based in the school curriculum. Birman et al. (2000) concur, emphasising that a focus in the teaching context, with coherence within a broad, rather than narrow, set of opportunities for teacher learning, and with active learning will, with time, engender meaningful and deep intellectual development. Deep learning requires intrinsic motivation stimulated by tasks of optimal novelty and difficulty that are relevant to personal interests of beginning geography teachers and that consequently allow for a degree of personal choice and control. It is recognised that beginning teachers move at different rates and along different pathways towards competence. Learning to teach is a process that is person specific (Brookfield, 1987). It involves a strongly emotional as well as cognitive dimension. As a journey, it is risky for both the new teacher and the tutor or mentor. Sparked by intended or unintended triggers, it often gives rise to unexpected but, nonetheless, valuable outcomes. The process must be user-friendly, meaningful, and help participants feel included and more competent in the career upon which they are about to embark. Above all, the effective training of geography teachers requires self-directed learning if the goal of the knowledgeable, responsible and autonomous geography teacher is to be achieved.

Despite the rhetoric, much of the philosophy underlying the training of geography teachers has been craft directed with modules, for instance, in microteaching, IT skills and planning. The shift now is more towards an experiential, problem-solving perspective facilitated by the development of problem-based learning. Problem-based learning (PBL) is one approach for the preparation of beginning geography teachers that is focused in this way. Ayers (2002) notes that PBL consists of carefully selected problems/issues/cases/scenarios related to the objectives of learning in which the learner acquires the critical knowledge 
and skills of problem solving, self-directed learning strategies and team participation. The process replicates the commonly used systemic approaches to resolving problems or meeting challenges encountered in a career. It is 'an approach to learning in which problems serve as the stimulus for students to gain course concepts and content as well as meta-cognitive skills' (Major, 1999: 7). Using PBL, a range of problems / issues / cases / scenarios related to the objectives of teaching and learning geography in the school are confronted, through which the student teachers take a major responsibility for their own learning and decision making. In working through problems, beginning geography teachers come to (1) understand concepts and principles related to learning of how to teach geography as a constructive process which embraces the development of high-order thinking, thinking dispositions, strategies for learning and meta-cognition; and (2) apply these concepts and principles in addressing typical classroom learning dilemmas faced in teaching geography (Kwan \& Stimpson, 2004). PBL involves the questioning of assumptions and the application of theories and evidence that individuals see as relevant to the construction of the their own personal theory of geography teaching. Overall, while problem-based learning is not the only approach that might be used and may not be the most appropriate in, say, dealing with technical skills, there are considerable benefits to be gained in content knowledge and in enhanced skills of critical thinking, problem solving, research and communication.

What should be the meat of training? Where should the focus of knowledge underlying the problems be? Knowledge of subject matter, educational aims, curriculum, learners and general pedagogy are essential but none are sufficient on their own. Shulman (1986) argued that pedagogical content knowledge, which interprets these in classroom application through 'the ways of representing and formulating the subject that make it comprehensible to others' (p.9) is perhaps at the heart of what a competent teacher should acquire. It integrates, in particular, subject understanding, curriculum content, pedagogy and a knowledge of learners. It is concerned with more than technical issues and brings into focus the stories, analogies, lines of argument and examples that give meaning to students. The construct, though diffuse, is straightforward, but for the young geographer starting out on a teaching career it can seem complex, daunting and subject to a variety of tensions brought about by competing forces. The process of developing pedagogical content knowledge is fraught with difficulty as beginning teachers struggle to accommodate varying views and perspectives into a personal theory of classroom practice that will allow them to become established. Whereas information about the curriculum, educational theories of learning and organisational structures are largely new when they enter training, pedagogy and subject content have already been experienced when at school. The beginning teacher comes to training with an incipient personal theory and a set of assumptions that encapsulate what should be taught and how. This may match that promoted in teacher training programmes and in practice schools or, as is often the case given the evolving nature of curricula, may not. This is the dilemma and challenge for those organising learning to teach.

A third component in line with the notion of experiential, problem-based, situated learning in the classroom is a focus in the school. Part-time PGDE students engage in this to a degree but are without the mentorship necessary to provide 
support in the process of critical reflection on practice. Full-time PGDE students have been progressively moving from a position in which practice in school was largely separate from university-based learning to an integrated position within a rhetoric of school-university partnership. As well as extended classroom practice, PGDE students spend a day a week in school throughout the course supported by a mentor in a pattern similar to that used in the UK or Australia, for example. As in these educational systems, problems have been experienced in regard to school readiness and mentor receptivity. Lacking a mandated or funded mentoring provision, what is on offer is highly variable, ranging from the very supportive to a 'sink or swim' mentality. Mentor training has been crucial and is slowly changing hearts and minds.

\section{Conclusion}

This paper has attempted to illuminate the thinking and direction in the initial training of geography teachers in Hong Kong as these incipient professionals negotiate entry and identity into a community of practice. The task is recognised as a challenging one for trainers and trainees alike. Compromises have to be made between providing beginning geography teachers room to develop in their own ways and at the same time meet the needs of the classroom demanded by certification. Most of all, we have come to recognise that training the trainers both in schools and in the universities is central if leadership is to be provided and opportunities for curriculum change realised.

\section{Correspondence}

Any correspondence should be directed to Dr Philip Stimpson, Faculty of Education, The University of Hong Kong, Hong Kong (hraspgs@hkucc.hku.hk).

\section{References}

Ayers, F. (2002) Problem-based learning: The benefits to students and organisations. Training Journal (February). On WWW at http: / / www.trainingjournal.com/ abstract / 2002/30202.htm. Accessed 12.03.

Birman, B.F., Desimone, L., Porter, A.C. and Garet, M.S. (2000) Designing professional development works. Educational Leadership 57 (8), 4-14.

Brookfield, S.D. (1987) Developing Critical Thinkers: Challenging Adults to Explore Alternative Ways of Thinking and Acting. Buckingham: Open University Press.

Kwan, T.Y.L and Stimpson, P.G. (2004) Initial training of geography teachers: Knowledge and approach. In A. Kent, E. Rawling and A. Robinson (eds) Expanding Horizons in a Shrinking World. Published jointly by the IGU-CGE British Sub-Committee and the Scottish Association of Geography Teachers (pp. 120-23).

Major, C. (1999) Connecting what we know and what we do through problem-based learning. American Association for Higher Education Bulletin 51 (7), 7-9.

Shulman, L.S. (1986) Those who understand: Knowledge growth in teaching. Educational Researcher 15 (2), 4-14.

Willis, S. (2002) Creating a knowledge base for teaching. Educational Leadership 59 (6), 6-12. 